\title{
Authors' reply to the published comment regarding our article: Application of the new SMS system of cochleovestibular anomalies: our experience with nine cases of type III anomaly
}

\author{
Mohnish Grover $^{1} \cdot$ Anupam Kanodia $^{2}$ D $\cdot$ Gaurav Gupta $^{3} \cdot$ Chappity Preetam $^{4} \cdot$ Sunil Samdani $^{1}$
}

Received: 30 April 2021 / Accepted: 3 May 2021 / Published online: 27 May 2021

(c) The Author(s), under exclusive licence to Springer-Verlag GmbH Germany, part of Springer Nature 2021

Dear editor,

We would like to offer a clarification over a statement that we wrote in our article [1]. We had mentioned in our article that Sennaroglu et al. did not report a gusher in their 14 reported cases of IP-I [2]. If one reviews that article by our esteemed colleague, the text on page number 23 under the heading 'CSF gusher' mentions that 'It is interesting that none of the 4 patients with a common cavity and none of the 14 patients with IP-I who were operated on had a CSF gusher' which was our source of misinterpretation. The subsequent table on page no 24 of the same article mentions that 9 cases of IP-I indeed had CSF gusher.

We hope the above explanation clears any confusion in this regard.

\section{Declarations}

Conflict of interest The authors declare that they have no conflict of interest.

\section{References}

1. Grover M, Kanodia A, Gupta G, Preetam C, Samdani S (2021) Application of the new SMS system of cochleovestibular anomalies: our experience with nine cases of type III anomaly. Eur Arch oto-rhino-laryngology 278(3):659-664

2. Sennaroglu L (2010) Cochlear implantation in inner ear malformations-a review article. Cochlear Implants Int [Internet] 11(1):4-41. https://doi.org/10.1002/cii.416

Publisher's Note Springer Nature remains neutral with regard to jurisdictional claims in published maps and institutional affiliations.

This reply refers to the comment available online at https://doi.org/ 10.1007/s00405-020-06592-6.

Anupam Kanodia

Kanodiaanupam@gmail.com

1 Department of ENT and Head-Neck Surgery, SMS Medical College and Hospital, Jaipur, Rajasthan, India

2 Department of ENT and Head-Neck Surgery, All India Institute of Medical Sciences, New Delhi, India

3 Department of ENT and Head-Neck Surgery, Sardar Patel Medical College, Bikaner, Rajasthan, India

4 Department of ENT and Head-Neck Surgery, All India Institute of Medical Sciences, Bhubaneshwar, India 